\title{
Monitoramento de macrófitas aquáticas no rio São Francisco no trecho urbano de Petrolina-PE
}

Monitoring of aquatic macrophytes in São Francisco river in an urban stretch of Petrolina - PE

\author{
R. T. A. Minhoni; M. H. C. Souza; R. D. S. Santos; C. R. L. Zimback \\ Departamento de Solos e Ciências Ambientais, Universidade Estadual Paulista,18.610-307, Botucatu-SP, Brasil
}

renataminhoni@hotmail.com

(Recebido em 02 de agosto de 2017; aceito em 16 de março de 2018)

\begin{abstract}
A bacia do rio São Francisco é a terceira mais importante no Brasil e engloba 521 municípios. Dentre os municípios banhados pelo rio São Francisco, destaca-se Petrolina-PE e Juazeiro-BA, pertencentes à Região do Vale do São Francisco, considerada no cenário nacional, como sendo um dos principais polos exportadores de frutas. Toda essa produção agrícola gera efluentes contaminados com agroquímicos que, somados aos lançamentos de esgotos urbanos e industriais, vêm comprometendo a qualidade das águas do rio São Francisco e favorecendo a proliferação de macrófitas aquáticas nas margens do rio. O objetivo desse trabalho foi quantificar a evolução da área ocupada por macrófitas aquáticas, no período compreendido entre 2013 a 2016, em um trecho urbano de 11 km de extensão, situado às margens do rio São Francisco, nos municípios de Petrolina-PE e Juazeiro-BA. Para quantificar essa área foram utilizadas quatro imagens do satélite LANDSAT-8/OLI. As imagens passaram por um processo de classificação supervisionada, a partir do qual, foram gerados os mapas temáticos, representando a distribuição espacial da ocupação pela vegetação. Verificou-se maior adensamento da vegetação aquática na margem esquerda (Petrolina-PE) do rio São Francisco. No período compreendido entre os anos de 2013 a 2016, houve um aumento de aproximadamente $53 \%$ na área ocupada pelas macrófitas aquáticas no trecho estudado do rio São Francisco. A utilização de imagens de satélites e ferramentas do geoprocessamento mostraram-se eficientes, na quantificação de áreas ocupadas por vegetação aquática.

Palavras-chave: landsat-8, sensoriamento remoto, classificação supervisionada.
\end{abstract}

The São Francisco watershed is the third most important in Brazil and encompasses 521 cities. Among the cities bathed by the São Francisco river, Petrolina-PE and Juazeiro-BA, belonging to the Region of the São Francisco Valley, considered in the national scenario, are one of the main exporters of fruit. All this agricultural production generates effluents contaminated with agrochemicals, which added to the releases of urban and industrial sewage, have been compromising the quality of the waters of the São Francisco river and favoring the proliferation of aquatic macrophytes on the banks of the river. This work aims to quantify the evolution of the area occupied by aquatic macrophytes, in the period between 2013 to 2016, in an urban stretch of $11 \mathrm{~km}$ long, located on the banks of the São Francisco river, in the cities of PetrolinaPE and Juazeiro-BA. To quantify this area four images of the LANDSAT-8/OLI satellite were used. The images underwent a supervised classification process, from which the thematic maps were generated, representing the spatial distribution of the occupation by the vegetation. It was verified a greater accumulation of aquatic vegetation in the left bank (Petrolina-PE) of the São Francisco river. In the period from 2013 to 2016, there was an increase of approximately 53\% in the area occupied by the aquatic macrophytes in the studied section of the São Francisco river. The use of satellite images and geoprocessing tools proved to be efficient in the quantification of areas occupied by aquatic vegetation.

Keywords:landsat-8, remote sensing, supervised classification.

\section{INTRODUÇÃO}

O rio São Francisco possui $2.700 \mathrm{~km}$ de extensão, com nascente na Serra da Canastra-MG e escoamento sentido Sul-Norte pela Bahia e Pernambuco, desembocando no Oceano Atlântico na divisa entre os estados de Alagoas e Sergipe. A bacia do rio São Francisco é a terceira mais importante no Brasil [1,2].

A região percorrida pelo rio divide-se em Alto, Médio, Sub médio e Baixo São Francisco. A Região Hidrográfica do São Francisco engloba 521 municípios, nos estados da Bahia, Minas Gerais, Pernambuco, Alagoas, Sergipe, Goiás e Distrito Federal [1,3]. 
Dentre os munícipios banhados pelo rio São Francisco, destacam-se Petrolina-PE e JuazeiroBA, localizados na Região do Vale do São Francisco, mais especificamente no Sub médio São Francisco, considerada no cenário nacional, como sendo um dos principais polos exportadores de uva e manga e o segundo maior produtor de vinhos finos [4,5].

Assim, para se manter nesse cenário, faz-se necessário, a utilização de grandes quantidades de insumos agrícolas e de agrotóxicos para combater pragas e doenças, gerando passivos ambientais, como por exemplo, efluentes e águas de drenagem contaminadas com produtos químicos.

Além da poluição causada pelas atividades agrícolas, a bacia também recebe despejos de efluentes urbanos e industriais. Dos 456 municípios, com sede na bacia hidrográfica do São Francisco, somente 93 tratam seus esgotos [1].

Todo esse lançamento de efluentes compromete a qualidade da água, alterando suas características físicas, químicas e microbiológicas. O aumento da concentração de nutrientes na água pode favorecer o crescimento excessivo de algas e/ou a infestação de macrófitas aquáticas.

A proliferação de macrófitas aquáticas pode comprometer os usos múltiplos de ecossistemas aquáticos, além de causar uma série de problemas. Dentre os problemas mais comumente observados podem ser citados, poluição visual; redução da biodiversidade; comprometimento dos esportes náuticos; entupimento de tubulações e canais de irrigação; e prejuízos à produção de energia em usinas hidrelétricas $[6,7,8,9,10,11,12,13]$.

Assim, é extremamente importante realizar estudos exploratórios, visando identificar e quantificar áreas ocupadas por macrófitas aquáticas, para que tais estudos sirvam como base no gerenciamento e manejo das áreas afetadas, mitigando e /ou evitando danos socioeconômicos e ambientais.

O monitoramento de macrófitas aquáticas em corpos hídricos, realizado por meio de metodologias convencionais, torna-se uma tarefa lenta e com custos elevados $[14,15]$.

Em contra partida, a utilização de técnicas de sensoriamento remoto e imagens de satélites, têm-se mostrado uma alternativa bastante promissora, no que diz respeito ao monitoramento da proliferação de macrófitas aquáticas [16,17,18,19,20, 21].

O emprego do sensoriamento remoto é de fundamental importância no monitoramento da cobertura vegetal em lagos e rios, como alternativa viável na obtenção de informações a respeito, o que facilita a identificação de pontos de lançamentos de efluentes e/ou outros aspectos a serem avaliados [21].

Diante do exposto, esse trabalho objetivou quantificar por meio de classificação supervisionada, a evolução da área ocupada por macrófitas aquáticas, no período compreendido entre 2013 a 2016, em um trecho urbano situado as margens do rio São Francisco, nos municípios de Petrolina-PE e Juazeiro-BA.

\section{MATERIAL E MÉTODOS}

Para a realização deste trabalho selecionou-se um trecho do rio São Francisco, mais especificamente na Região do Sub médio São Francisco, ao longo da área urbana das cidades de Petrolina (PE) e Juazeiro (BA) (Figura 1), aonde apresenta expressiva incidência de macrófitas aquáticas (Figura 2). Este trecho possui um comprimento de cerca de $11 \mathrm{~km}$ e está localizado aproximadamente nas coordenadas $40^{\circ} 26^{\prime} \mathrm{O}$ e $9^{\circ} 22^{\prime} \mathrm{S}$ a $40^{\circ} 32^{\prime} \mathrm{O}$ e $9^{\circ} 25^{\prime} \mathrm{S}$ (Datum horizontal: SIRGAS 2000). 


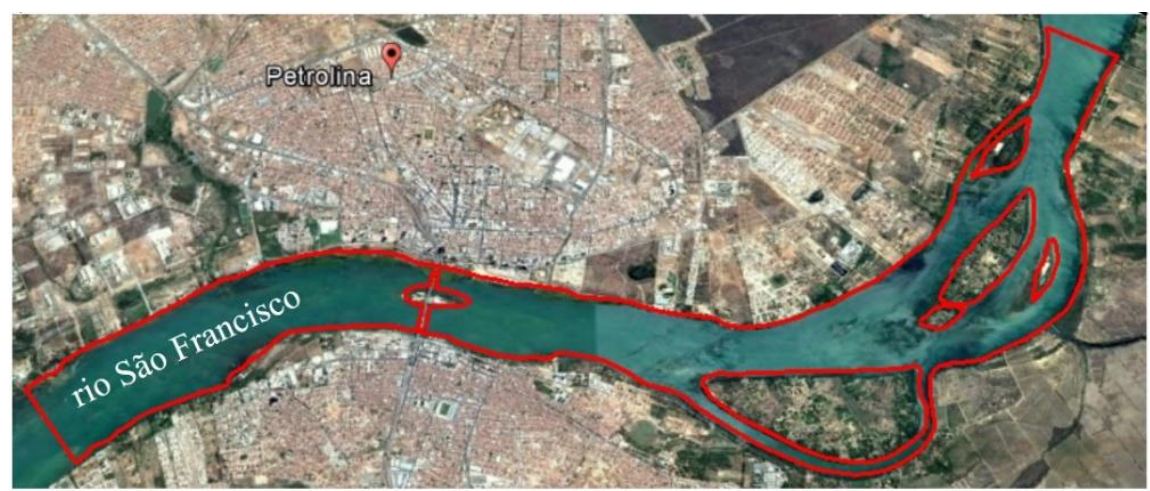

Legenda:

Área de estudo

Figura 1. Localização da área de estudo.

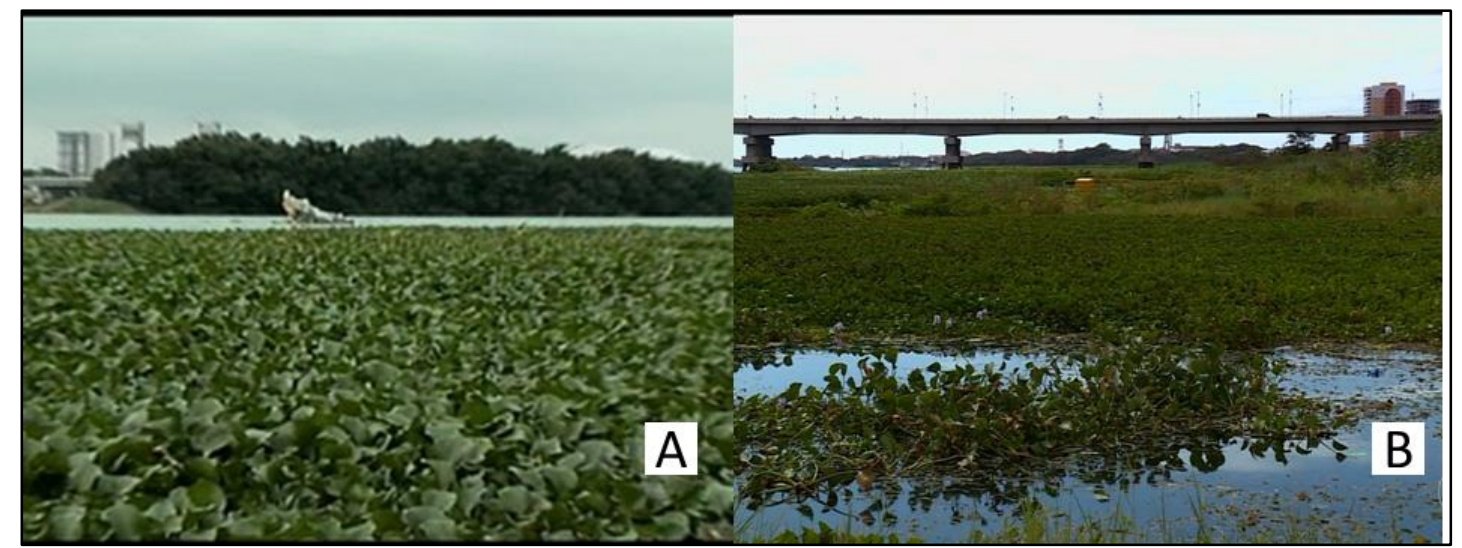

Figura 2: Macrófitas aquáticas nas margens do Rio São Francisco em 2014 (A) e 2016 (B). Fonte: [22].

Para quantificar a área ocupada por macrófitas aquáticas no trecho estudado do rio São Francisco foram utilizadas quatro imagens do satélite LANDSAT-8/OLI, sendo elas referentes aos anos de 2013 a 2016, mais especificamente de 03/09/2013, 22/09/2014, 09/09/2015 e 10/08/2016, vale ressaltar que, todas essas datas compreendem, segundo dados históricos climatológicos, o período seco, ou seja, com baixa ocorrência ou inexistência de precipitação na Região.

A aquisição das imagens foi realizada por meio do site do USGS (United States Geological Survey), que fornece as imagens gratuitamente. Na Tabela 1 estão apresentadas as características das imagens selecionadas, com órbita/ponto 217/66.

Tabela 1. Características das imagens do satélite LANDSAT-8, sensor OLI.

\begin{tabular}{cccc}
\hline Banda & Espectro & $\begin{array}{c}\text { Comprimento de onda } \\
(\boldsymbol{\mu} \mathbf{m})\end{array}$ & $\begin{array}{c}\text { Resolução espacial } \\
(\mathbf{m})\end{array}$ \\
\hline Banda 2 & Azul & $0,45-0,51$ & 30 \\
Banda 3 & Verde & $0,53-0,59$ & 30 \\
Banda 4 & Vermelho & $0,64-0,67$ & 30 \\
Banda 5 & IV Próximo & $0,85-0,88$ & 30 \\
Banda 6 & SWIR 1 & $1,57-1,65$ & 30 \\
Banda 7 & SWIR 2 & $2,11-2,29$ & 30 \\
Banda 8 & Pancromático & $0,50-0,68$ & 15 \\
\hline
\end{tabular}

Fonte: USGS [23]. 
Foram selecionadas imagens livres da incidência de nuvens, na época seca referentes aos meses de setembro e agosto, devido ao menor volume de chuvas e, consequente, maior proliferação de macrófitas aquáticas.

As principais etapas realizadas para a obtenção dos produtos finais deste trabalho são apresentadas por meio de um fluxograma da metodologia empregada, conforme mostrado na Figura 3.

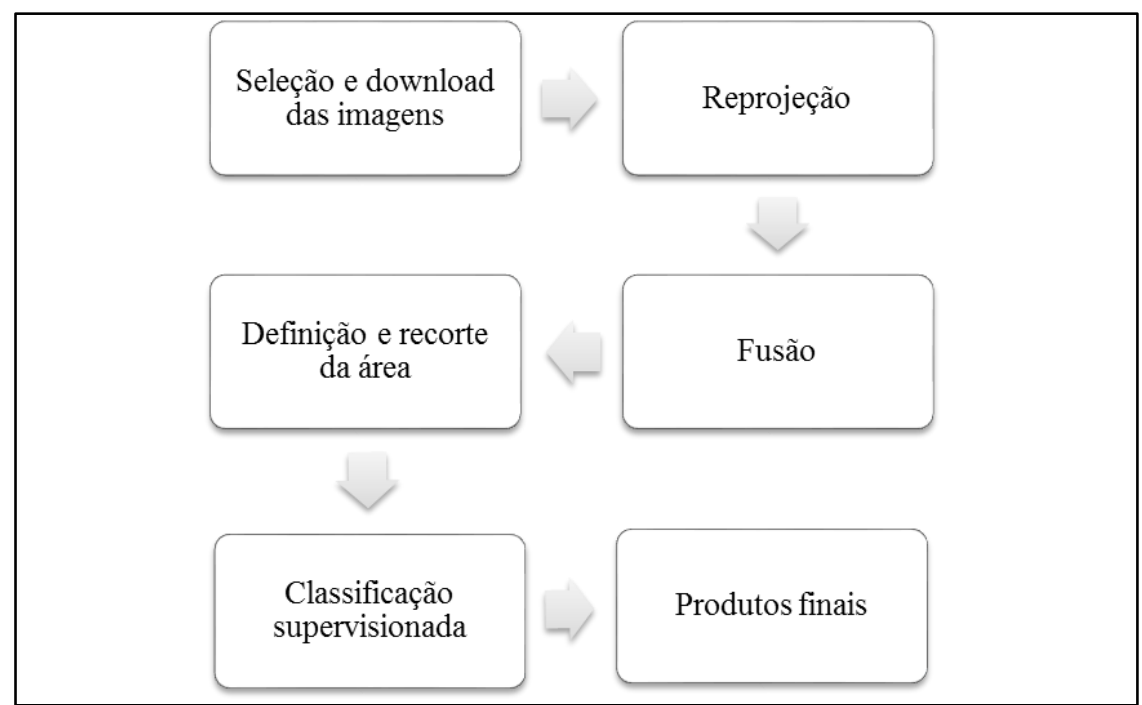

Figura 3. Fluxograma da metodologia empregada.

Estando as imagens originais projetadas no hemisfério norte, realizou-se a reprojeção para o hemisfério sul. Após a reprojeção, foi realizada a fusão das bandas multiespectrais, resolução espacial de $30 \mathrm{~m}$, com a banda pancromática, resolução espacial de $15 \mathrm{~m}$, com objetivo de melhorar a resolução espacial. O processo de fusão de imagens foi realizado no programa Orfeo Toolbox.

Foi definido o limite do trecho estudado e o posterior recorte das imagens. Durante o recorte foram retiradas da área as ilhas e a ponte que faz a ligação entre Petrolina-PE e Juazeiro-BA, restando apenas uma área composta por água e macrófitas aquáticas.

Após o recorte das imagens, foi elaborada a classificação supervisionada. Neste processo foram coletadas assinaturas espectrais de regiões específicas da imagem por meio da delimitação de polígonos e, em seguida, essas assinaturas espectrais foram empregadas na classificação de todos os pixels da imagem [24]. Na etapa de criação dos polígonos foram utilizadas imagens do Google Earth, com maior resolução espectral, com o intuito de auxiliar na distinção das classes avaliadas.

A classificação supervisionada foi realizada por meio de algoritmos, onde a identificação dos padrões espectrais de uma imagem é baseada em polígonos de treinamento, os quais foram fornecidos pelo operador do sistema no momento da classificação [25].

$\mathrm{Na}$ classificação das imagens, foi utilizado o algoritmo Maximum Likelihood, conhecido como algoritmo de Máximo Verossimilhança (MAXVER). Este algoritmo classifica cada pixel desconhecido de uma imagem à classe de maior probabilidade, a partir de critérios prévios definidos pelo operador da classificação [26].

Todas as imagens foram mapeadas de acordo com sua classe, gerando assim os mapas temáticos, representando a distribuição espacial da ocupação pelas macrófitas na área analisada.

\section{RESULTADOS E DISCUSSÃO}

Nas Figuras 4, 5, 6 e 7 estão apresentados os produtos da classificação supervisionada para os anos 2013, 2014, 2015 e 2016, respectivamente. Verificou-se maior adensamento de macrófitas aquáticas na margem esquerda do rio São Francisco, possivelmente devido ao lançamento de efluente não tratado, com elevado teor de nutrientes. 


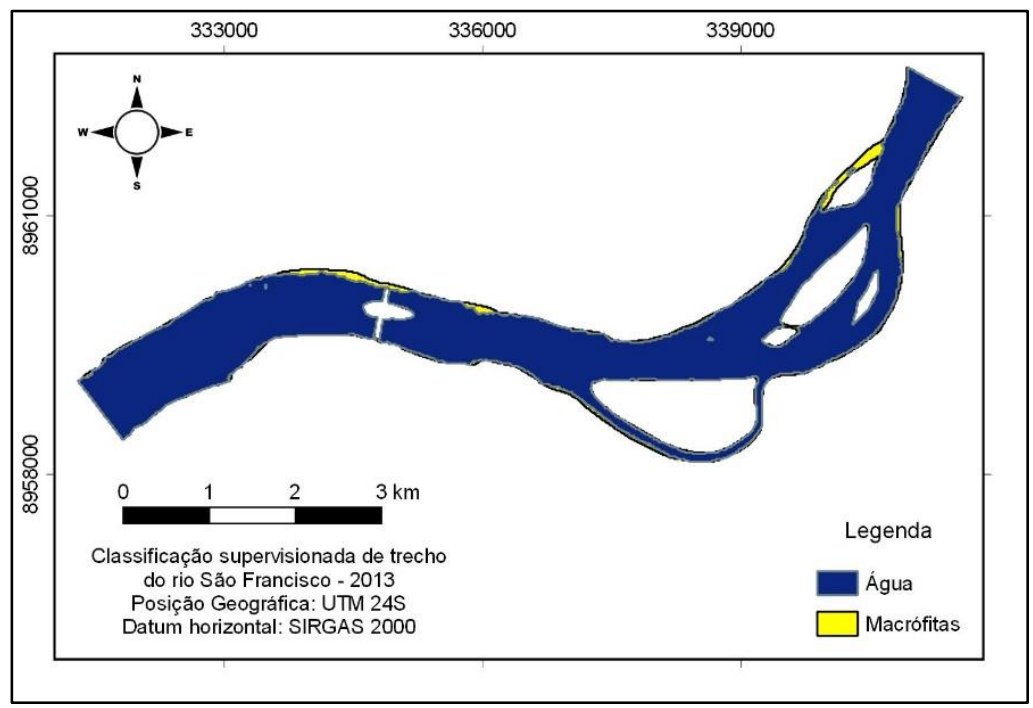

Figura 4. Mapa de classificação supervisionada para o ano de 2013.

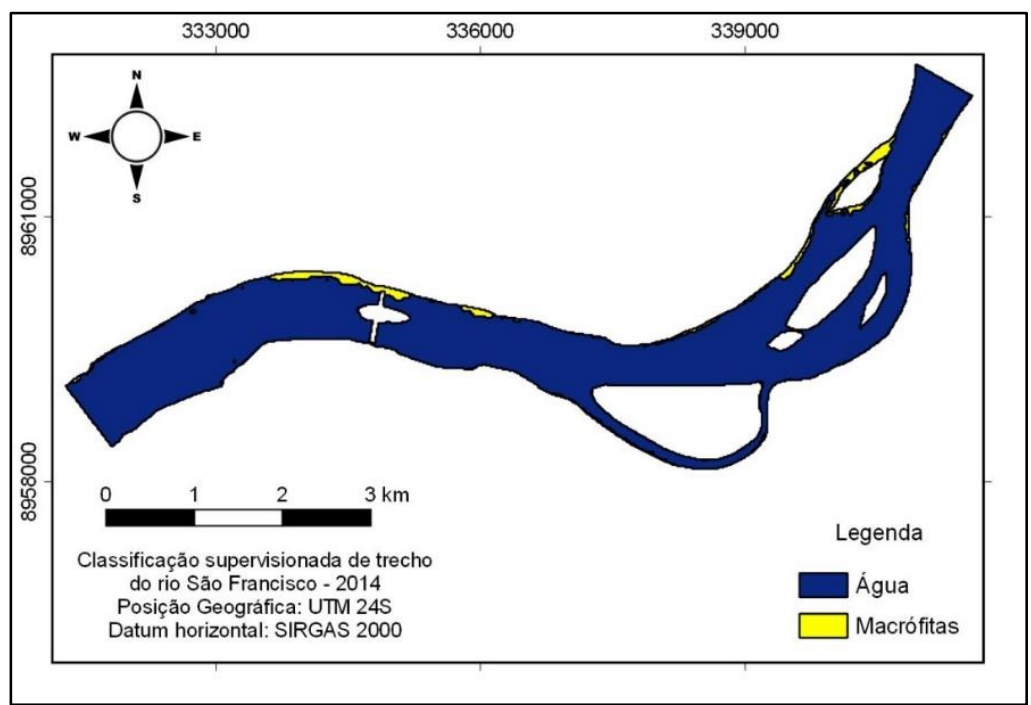

Figura 5. Mapa de classificação supervisionada para o ano de 2014. 


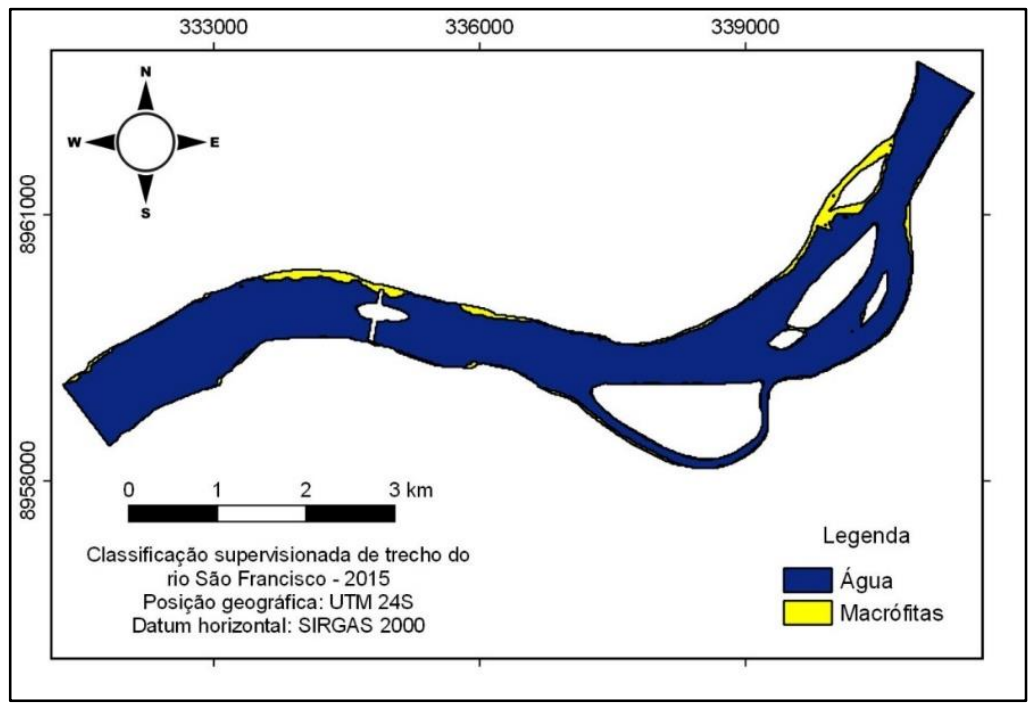

Figura 6. Mapa de classificação supervisionada para o ano de 2015.

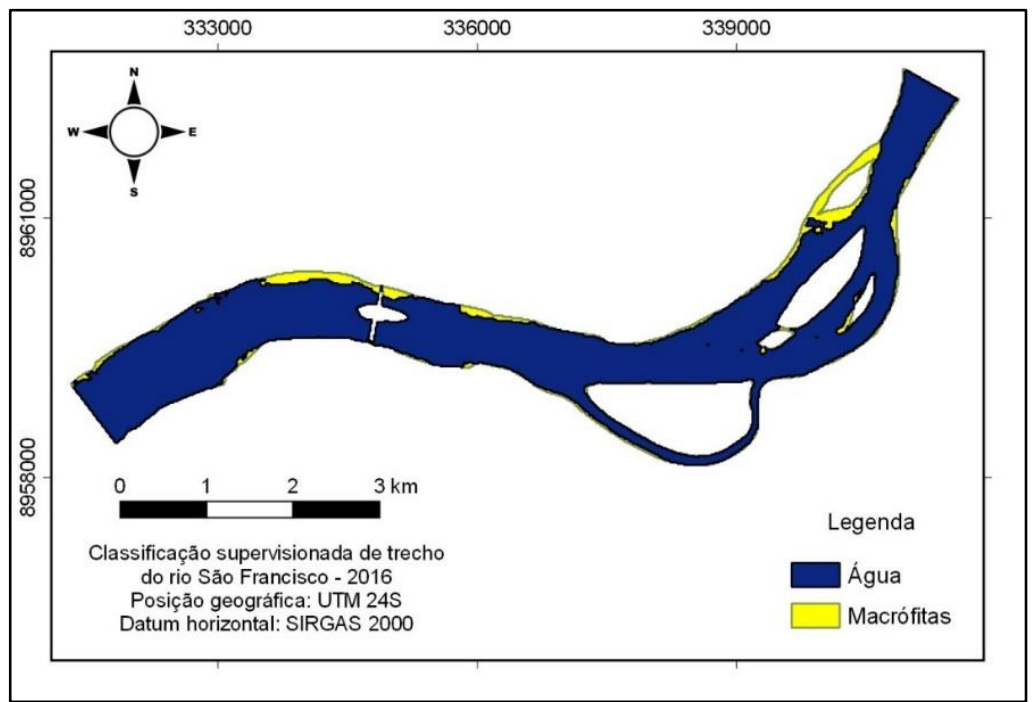

Figura 7. Mapa de classificação supervisionada para o ano de 2016.

Está apresentada na Figura 8 a evolução temporal da ocupação de macrófitas aquáticas no trecho do rio São Francisco, no período de 2013 a 2016. A área ocupada pelas macrófitas no ano de 2013 foi aproximadamente 52,2 ha, o equivalente a cerca de 5,8\% do trecho estudado. No ano de 2014 a área ocupada foi de aproximadamente 39,9 ha. Em 2015 e 2016 a área ocupada pelas macrófitas aumentou para 74,7 ha e 79,9 ha, respectivamente. 


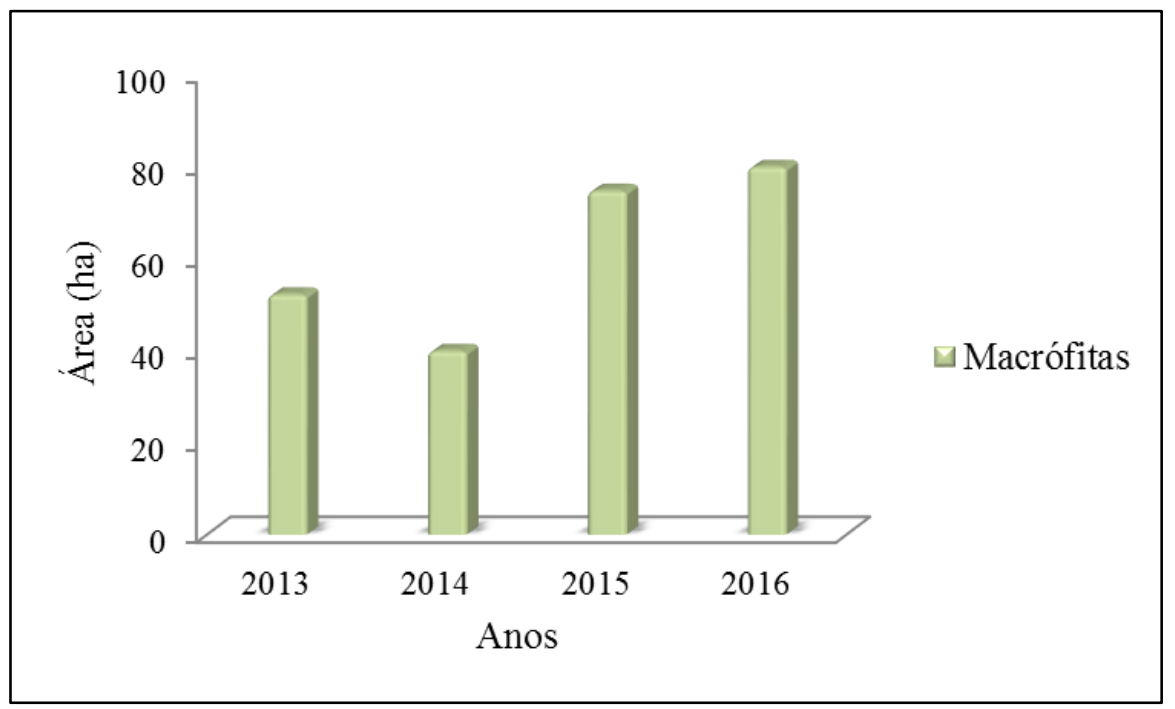

Figura 8. Evolução da área ocupada pelas macrófitas, nos anos de 2013, 2014, 2015 e 2016.

No geral, no período compreendido entre os anos de 2013 a 2016, houve um aumento de aproximadamente 53\% na área ocupada pelas macrófitas aquáticas no trecho estudado do rio São Francisco.

Existem duas possíveis justificativas para essa redução da área ocupada por macrófitas aquáticas no ano de 2014, ambas ocorreram em sequência, diferentemente dos demais anos estudados. A primeira seria a retirada dessa vegetação durante as limpezas realizadas pela Prefeitura de Petrolina-PE na área em estudo. Em consulta bibliográfica, constatou-se que geralmente essas limpezas ocorrem no mês de dezembro. A segunda justificativa consiste na ocorrência atípica de elevada precipitação (Figura 9) no início do ano de 2014, o que favorece a diluição da carga orgânica despejada no rio e, consequentemente, o carreamento de nutrientes, devido à elevação da vazão de escoamento da água no rio.

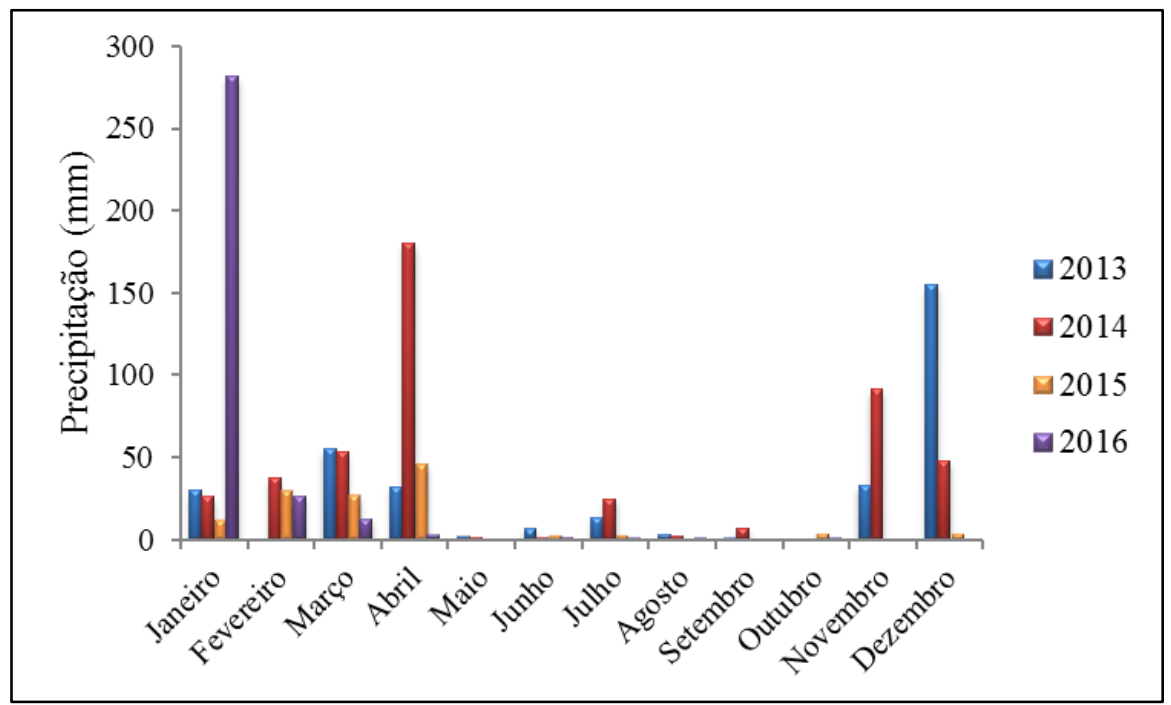

Figura 9: Precipitação mensal entre os anos de 2013 e 2016. Fonte: [27].

É notável o aumento da área ocupada por macrófitas ao longo dos quatro anos analisados, o que pode ter ocorrido devido à baixa velocidade de escoamento da água e/ou assoreamento (reduz a profundidade) do trecho do rio que margeia a cidade de Petrolina-PE. Na margem oposta (Juazeiro-BA) não há grande proliferação de macrófitas, esse lado apresenta maior velocidade de escoamento da água e maior profundidade quando comparado com o lado de Petrolina, o que favorece o tráfego de embarcações e justifica a menor incidência dessa vegetação aquática. 
Em um estudo abrangendo nove pontos amostrais do rio São Francisco, dentro da mesma área analisada neste trabalho, objetivou-se determinar o índice de estado trófico (IET) desses pontos, os quais são pontos de lançamento de esgoto tratado e/ou bruto e localizados a montante e/ou jusante de pontos de lançamento de efluentes [28].

Segundo os mesmos autores, em todos os pontos analisados, os teores de fósforo foram superiores aos limites estabelecidos pela Resolução CONAMA 357/05 [29]. Com relação ao nitrogênio total, apenas no ponto de lançamento de esgoto bruto, o limite foi excedido. Elevadas concentrações de nitrogênio e fósforo são as principais causas da eutrofização no meio aquático, pois esses nutrientes são essenciais ao metabolismo das algas e microrganismos [30,31].

Em termos de estado trófico, ou seja, carga orgânica, corroboram os resultados encontrados nesse trabalho. O lançamento de esgoto em corpos hídricos favorece a proliferação de macrófitas aquáticas [28].

Outro estudo também relatou situações semelhantes as encontradas neste trabalho, correlacionando a elevada incidência de macrófitas aquáticas com elevadas concentrações de material orgânico, rico em nitrogênio e fósforo [12].

\section{CONCLUSÃO}

A partir dos produtos gerados na classificação supervisionada do trecho estudado do rio São Francisco, é possível afirmar que houve um incremento da área ocupada por macrófitas aquáticas no período de 2013 a 2016, com apenas uma redução em 2014, provavelmente devido à limpeza da área pelo órgão público e elevadas precipitações locais.

A utilização de imagens de satélites e ferramentas do geoprocessamento mostraram-se eficientes, na quantificação de áreas ocupadas por macrófitas aquáticas.

Os mapas confeccionados podem auxiliar na identificação da dinâmica espacial e temporal das macrófitas no local, promovendo um suporte a órgãos de monitoramento ambiental da região, além de facilitar o desenvolvimento de estratégias para o manejo adequado das macrófitas.

\section{REFERÊNCIAS BIBLIOGRÁFICAS}

1. ANA - AGÊNCIA NACIONAL DE ÁGUAS. Região Hidrográfica do São Francisco. Disponível em: <http://www2.ana.gov.br/Paginas/portais/bacias/SaoFrancisco.aspx>. Acesso em: 10 nov. 2016.

2. MMA - Ministério do Meio Ambiente. Caderno da Região Hidrográfica do São Francisco. Ministério do Meio Ambiente. Brasília: Secretaria de Recursos Hídricos; 2006. 148 p.

3. Portal São Francisco. Hidrografia do Brasil. Disponível em: $\langle$ http://www.portalsaofrancisco.com.br/alfa/meio-ambiente-agua/hidrografia-do-brasil.php〉. Acesso em: 01 out. 2016.

4. MAPA - Ministério da Agricultura, Pecuária e Abastecimento. Estatística. Disponível em: <www.agrcultura.gov.br>. Acesso em: 20 out. 2016.

5. Agrianual. Anuário Brasileiro da Uva e Vinho. Santa Cruz do Sul: Editora Gazeta Santa Cruz; 2006. $128 \mathrm{p}$.

6. Winton MD, Clayton JS. The impact of invasive submerged weed species on seed banks in lake sediments. Aquatic Botany. 1996;53:31-45, doi:10.1016/0304-3770(95)01010-6.

7. Thomaz SM, Bini LM. A expansão das macrófitas aquáticas e implicações para o manejo de reservatórios: um estudo na represa de Itaipu. In: Henry R. Ecologia de reservatórios: estrutura, função e aspectos sociais. Botucatu: Fundibio; 1999. p. 597-626.

8. Thomaz SM. Fatores ecológicos associados à colonização e ao desenvolvimento de macrófitas aquáticas e desafios de manejo. Viçosa: Planta daninha. 2002;20(1):21-33, doi:10.1590/S010083582002000400003

9. Pompêo M. Monitoramento e manejo de macrófitas aquáticas em reservatórios tropicais brasileiros. São Paulo: Instituto de Biociências da USP; 2017, 138p., doi:10.11606/9788585658670

10. Bianchini JR I, Almeida AA, Fushita AT, Santino MBC, Maia AT. Monitoramento das macrófitas aquáticas do reservatório da usina hidrelétrica Luís Eduardo Magalhães (Estado de Tocantins, Brasil). Montevideo: Augmdomus. 2010;2:38-48. 
11. Rocha CMC, Alves AE, Cardoso AS, Cunha MCC. Macrófitas Aquáticas como Parâmetro no Monitoramento Ambiental da Qualidade da Água. Recife: Revista Brasileira de Geografia Física. 2012;5(4):970-983.

12. Mesquita FDO, Alves ADS, Malheiros SMM, Silva PCMD, Santos WDO, Batista RO. Uso do sensoriamento remoto para avaliação da distribuição espacial e quantificação de macrófitas na barragem Umari-Upanema, RN. Campina Grande: Agropecuária Científica no Semiárido. 2013;9(2):102-109.

13. Santarosa LV, Manzione RL, Gonçalves VFM. Análise da variação sazonal e espacial das macrófitas aquáticas presentes no reservatório da represa de Barra Bonita (SP) no ano hidrológico 2013-14. Anais XVII Simpósio Brasileiro de Sensoriamento Remoto - SBSR, 2015 Abr 25-29; João Pessoa-PB, Brasil, p. 5498-5505.

14. Luo C, Li X, Ma R, Li F, Duan H, Hu W, Qin B, Huang W. Applying remote sensing techniques to monitoring seasonal and interannual changes of aquatic vegetation in Taihu Lake, China. Ecological Indicators. 2016;60:503-513, doi:10.1016/j.ecolind.2015.07.029

15. Zhao D, Jiang H, Yang T, Cai Y, Xu D, An S. Remote sensing of aquatic vegetation distribution in Taihu Lake using an improved classification tree with modified thresholds. Journal of Environmental Management. 2012;95: 98-107, doi: 10.1016/j.jenvman.2011.10.007

16. Galo MLBT, Velini ED, Trindade MLB, Santos SCA. Uso do sensoriamento remoto orbital no monitoramento da dispersão de macrófitas nos reservatórios do Complexo Tietê. Viçosa: Planta Daninha. Edição Especial. 2002;20:7-20, doi:10.1590/S0100-83582002000400002

17. Rotta LHS, Imai NN, Boschi LS, Batista LFA. Detecção de macrófitas submersas por meio de imagem QuickBird - Estudo de Caso: Usina hidrelétrica de Porto Colômbia - MG/SP. Anais XV Simpósio Brasileiro de Sensoriamento Remoto - SBSR, 2011 Abr 30-Mai 05; Curitiba, PR, Brasil, p. 4460-4497.

18. Carvalho CA, Almeida T, Roig HL, Menezes PHBJ, Meneses PR. Identificação de paliteiros e macrófitas do Reservatório da UHE Luiz Eduardo Magalhães (TO) utilizando imagens R99SAR. Anais XV Simpósio Brasileiro de Sensoriamento Remoto - SBSR, 2011 Abr 30-Mai 05; Curitiba, PR, Brasil, p. 8121-8128.

19. Affonso AG, Novo EMLM, Queiroz HL. Dinâmica temporal da cobertura de macrófitas nos lagos de Mamirauá. Anais XVI Simpósio Brasileiro de Sensoriamento Remoto - SBSR, 2013 Abr 13-18; Foz do Iguaçu, PR, Brasil, p. 6387-6394.

20. Straškraba M, Tundisi, JG. Gerenciamento da qualidade da água de represas. São Paulo: Oficina de Textos; 2013. 300 p.

21. Santos LJS, Lemos OL, Candido PHV. Estimativa e comparação da área ocupada por plantas aquáticas no parque municipal lagoa das bateias, Vitória da Conquista- BA, entre 2008 e 2013. Goiânia: Enciclopédia Biosfera. 2015;11(21):984-996.

22. PORTAL G1 - A. Baronesas e resíduos serão retirados do Rio São Francisco em Petrolina, PE. Disponível em <http://g1.globo.com/pe/petrolina-regiao/noticia>. Acesso em: 01 nov. 2016.

23. USGS - United States Geological Survey. Disponível em: <https://www.usgs.gov/>. Acesso em: 23 out. 2016.

24. Sahebjalal E, Dashtekian K. Analysis of land use-land covers changes using normalized difference vegetation index (NDVI) differencing and classification methods. African Journal of Agricultural Research. 2013;8(37):4614-4622, doi:10.5897/AJAR11.1825

25. Moreira MA. Fundamentos do sensoriamento remoto e metodologias de aplicação.Viçosa: Ed. UFV; 2003. 307p.

26. Graciani SD, Novo EMLM. Determinação da cobertura de macrófitas aquáticas em reservatórios tropicais. INPE. Anais XI Simpósio Brasileiro de Sensoriamento Remoto - SBSR, 2003 Abr 05-10; Belo Horizonte, MG, Brasil, p. 2509-2516.

27. APAC - Agência Pernambucana de Águas e Clima. Monitoramento Pluviométrico. Disponível em: <http://www.apac.pe.gov.br/meteorologia/monitoramento-pluvio.php>. Acesso em: 01 nov. 2016.

28. Amorim MCC, Peres JM, Nascimento GSG, Belem J, Silva VSL. Estudos limnológicos do rio São Francisco em trecho urbano do município de Petrolina-PE. XIV IWRA World Water Congress, 2011Abr 25-29; Porto de Galinhas, PE, Brazil.

29. BRASIL, Resolução CONAMA n`357, de 17 de março de 2005. Conselho Nacional de Meio Ambiente. Disponível em: <http://www.mma.gov.br/port/conama/res/res05/res35705.pdf>. Acesso em: 05 mai. 2017.

30. Von Sperling M. Introdução à qualidade da Água e ao Tratamento de Esgotos. Belo Horizonte: Editora UFMG; 2014. 452 p.

31. Valdemir AR. Introdução ao Manejo de Microbacias. $4^{\circ}$ Simpósio Internacional em Manejo de Microbacias Hidrográficas: A década da água preconizada pela ONU, 2013 Jun 27-28; Botucatu, SP, Brasil. Disponível em: <http://www.fca.unesp.br/microbacias/introducao.html>. Acesso em: 01 nov. 2016. 